Int. J. Environ. Sci. Tech.

Vol. 2, No. 1, pp. 59-62, Spring 2005

\title{
Environmental importance of rhamnolipid production from molasses as a carbon source
}

\author{
${ }^{1 *}$ H. Rashedi, ${ }^{2}$ M. Mazaheri Assadi, ${ }^{1}$ B. Bonakdarpour, ${ }^{1}$ E. Jamshidi \\ ${ }^{1}$ Department of Chemical Engineering, AmirKabir University, Tehran, Iran \\ ${ }^{2}$ Biotechnology Center, Iranian Research Organization for Science and Technology, Tehran, Iran
}

\begin{abstract}
Rhamnolipid has been known as biosurfactant which is produced by Pseudomonas aeruginosa in fermentation process. Several carbon sources such as ethanol, glucose, vegetable oil and hydrocarbon have been used to produce rhamnolipid. In this study, we are trying to use molasses which is a waste product from sugar industry as carbon source to produce rhamnolipid. The bacterium which was previously isolated from Iranian oil over years Glycolipid production by isolated bacterium using sugar beet molasses as a carbon and energy source was investigated. Result from the study showed that the growth of the bacteria using molasses as carbon sources is growth-associated. The specific production rate of rhamnolipid with $2 \%, 4 \%, 6 \%, 8 \%$ and $10 \%$ of molasses are $0.00065,4.556,8.94,8.85$, and 9.09 respectively. The yield of rhamnolipid per biomass with $2 \%, 4 \%, 6 \%, 8 \%$ and $10 \%$ molasses are 0.003 , $0.009,0.053,0.041$ and 0.213 respectively. The production of rhamnolipid ( $0.0531 \mathrm{~g}$. rhamnolipid/g biomass) is higher compare to the culture grown in aerobic condition ( $0.04 \mathrm{~g}$. rhamnolipid/g biomass). These studies indicate that renewable, relatively inexpensive and easily available resources can be used for important biotechnological processes.
\end{abstract}

Key words: Biosurfactant, Pseudomonas aeruginosa, sugar beet molasses

*Corresponding Author, E-mail: rashedi@tco.ac.ir

\section{Introduction}

Surfactants and emulsifiers are widely used in the petroleum, pharmaceutical, cosmetic and food industries. Most of these compounds are chemically synthesized and it is only in the past few decades that surface-active molecules of biological origin have been described. At present biosurfactants are readily bio- degradable and can be produced from renewable and cheaper substrates, they might be able to replace their chemically synthesized counter parts. Among the heterogeneous group of biosurfactants, the rhamnose-containing glycolipids produced by Pseudomonas (Arinos, 1996). There is a recent increase of interest in the production of biosurfactants beacause of their biodegradability, reduced toxicity compared to synthetic surfactants and their application in enhanced oil recovery and food emulsification. The industrial demand for surfactants has grown to about $300 \%$ within the U.S. chemical industry during the last decade (Andre, 1998). Rapid advances in biotechnology over the past decades have led to considerable interest in the development of biological methods for manufacturing surfactants on the industrial scale. Various types of biosurfactant are synthesized by a number of microbes particularly during their growth on water-immiscible
substrates(Burgerm, 1963) A majority of biosurfactants are produced by bacteria. Among the bacteria, Pseudomonas species is well known for its capability to produce rhamnolipid biosurfactant with potential surface-active properties when grow on different carbon substrates. Rhamnolipid biosurfactants specifically produced by Pseudomonas aeruginosa in particular offer special advantages because of their potent emulsifying activity and low Critical Micelle Concentration. This particular bacteria (Pseudomonas aeruginosa) produces two types of glycolipids both containing rhamnose as the carbohydrate moiety. These glycolipids are produced after attaining the stationary phase when nitrogen is depleted in the medium (Babu, 1996). Rhamnolipid has been known as biosurfactant which is produced by Pseudomonas aeruginosa in fermentation process. It has been known that rhamnolipid has a strong potential to be used in industrial and bioremediation purposes (Chayabutra, et al., 2001). There are two structure of rhamnolipid which are L-Rhamnosyl-Lrhamnosyl- $\beta$-hydroxydecanoyl- $\beta$-hydroxydecanoate andL-rhamnosyl- $\beta$-hydroxydecanoyl- $\beta$ hydroxydecanoate. Several carbon sources such as 
ethanol, glucose, vegetable oil and hydrocarbon have been used to produce rhamnolipid under aerobic condition (Matsufuju, 1997). Molases which is known as waste product from sugar industry can be used as carbon source for rhamnolipid production. The nitrogen sources used by these bacteria are ammonium and nitrate salts. Oxygen has been used widely to produce rhamnolipid in fed batch, batch and continuous systems (Beeba, 1971). The weakness of aerobic fermentation in rhamnolipid production is the excess of foam formation which is due to bubble aeration and the presence of rhamnolipid.

This study aimed to look at the production of rhamnolipid by Pseudomonas aeruginosa using molasses as a carbon sourcess (Bai, 1998). The specific production rate and yield of rhamnolipid are explained as follows:

Growth associated specific production rate :

$Q p=Y_{P / X} \bullet \mu$

Yield

$Y_{P / X}=\frac{P 2-P 1}{X 2-X 1}$

Mixed-growth associated specific production rate

$Q p=Y_{P / X} \bullet \mu+\beta$

$\mathrm{Qp}=$ specific production rate of rhamnolipid (g/lh)

$\mathrm{Yp} / \mathrm{x}=$ yield of rhamnolipid

$\mu=$ specific growth rate $(1 / \mathrm{h})$

$\mathrm{P}=$ rhamnolipid concentration $(\mathrm{g} / \mathrm{l})$

$\mathrm{X}=$ biomass concentration $(\mathrm{g} / \mathrm{l})$

$\beta=$ production rate during stationary phase $(\mathrm{g} / \mathrm{l} \mathrm{h}$ )

This research has done in Biotech centerin Iranian Research Organization for science and echnology during years of 2004-2005

\section{Materials and Methods}

The bacterium used in this study "Pseudomonas aeruginosa" was isolated from Iranian well oil. The media used for the experiment are (g/l):

$\mathrm{NaNO}_{3}, 2.5 ; \mathrm{MgSO}_{4} .7 \mathrm{H}_{2} \mathrm{O}, 0.4 ; \mathrm{KCl}, 1 ; \mathrm{NaCl}, 1$; $\mathrm{CaCl}_{2} \cdot 2 \mathrm{H}_{2} \mathrm{O}, 0.05 ; \quad \mathrm{FeSO}_{4} \cdot 7 \mathrm{H}_{2} \mathrm{O}, 0.0005$; $\mathrm{ZnSO}_{4} .7 \mathrm{H}_{2} \mathrm{O}, 0.0015 ; \mathrm{MnSO}_{4} .7 \mathrm{H} 2 \mathrm{O}, 0.0015$; $\mathrm{H}_{3} \mathrm{BO}_{3}, \quad 0.0003 ; \quad \mathrm{CoCl}_{2} .6 \mathrm{H}_{2} \mathrm{O}, \quad 0.00015$; $\mathrm{CuSO}_{4} \cdot 5 \mathrm{H}_{2} \mathrm{O}, 0.00015 ; \mathrm{NaMoO}_{4} \cdot 2 \mathrm{H}_{2} \mathrm{O}$. 0.0001; $\mathrm{H}_{3} \mathrm{PO}_{4}, 1.71 \mathrm{~g} / \mathrm{ml}$. Molasses was used as carbon source at various concentrations. For fermentation processes Pseudomonas aeruginosa was cultivated at $30 \pm 1^{\circ} \mathrm{C}$ for $19 \mathrm{~h}$. at $200 \mathrm{rpm}$. in a 250 $\mathrm{ml}$. Erlenmeyer flask containing $50 \mathrm{ml}$. of seed medium: Nutrient Broth, $\mathrm{pH}$ 7.0. Seed culture (2\% $\mathrm{v} / \mathrm{v}, \mathrm{OD} 660=1.0$ ) was added into $1000 \mathrm{ml}$. Erlenmeyer flasks containing $200 \mathrm{ml}$. each of basal fermentation medium.

The $\mathrm{pH}$ of the culture supernatant fluid ( $3 \mathrm{ml}$.) obtained after removal of the cells by centrifugation (10000 g., $10 \mathrm{~min}$.) was adjusted to $\mathrm{pH}=2.0$ and allowed to stand overnight at $4{ }^{\circ} \mathrm{C}$, followed by extraction with a mixture of $\mathrm{CHCl}_{3}$ and $\mathrm{CH}_{3} \mathrm{COH}$ $(2: 1 \mathrm{v} / \mathrm{v})$. The solvent was evaporated and the residue dissolved in 0.1 mol. $\mathrm{NaHCO}_{3}(3 \mathrm{ml}$.).

\section{Results}

Biosurfactant production was studied using medium A, with \% molasses ( $\mathrm{v} / \mathrm{v}$ ) varying concentrations of molasses being used as the sole source of carbon. The biosurfactant production increased with the increase in the concentration of molasses and maximum production occurred when $7 \%(\mathrm{v} / \mathrm{v})$ of molasses were used (Figure 1).

Further increase in the concentration of molasses did not affect surfactant production significantly. However, the biomass increased with the increase in the concentration of molasses, as is evident from the whole cell protein. The increase in subtrate concentration (S) will result in the increase of specific growth rate $(\mu)$. This result can be seen in Figure 2 .

Table 1 shows that the specific production rate of rhamnolipid (Qp) is also related to the increase of substrate concentration (S). The nitrate uptakes were e" $90 \%$ in all substrate concentration except in $4 \%$ of molasses, as can be seen in Figure3.

There is not any scientific approach to explain the exceptional. The yield of rhamnolipid produced by the medium at $6 \%, 8 \%$ and $10 \%$ concentration of molasses is higher when compare with other study which used $30 \mathrm{~g} / \mathrm{l}$ glucose. The result of the yield can be seen at Table 2 .

Table1: Relation between molasses concentration and specific production rate

\begin{tabular}{|c|c|}
\hline Concentration of Molasses & Qp (g/l.h) \\
\hline $2 \%$ & 0.00065 \\
$4 \%$ & 4.555674 \\
$6 \%$ & 8.941563 \\
$8 \%$ & 8.850229 \\
$10 \%$ & 9.092182 \\
\hline
\end{tabular}




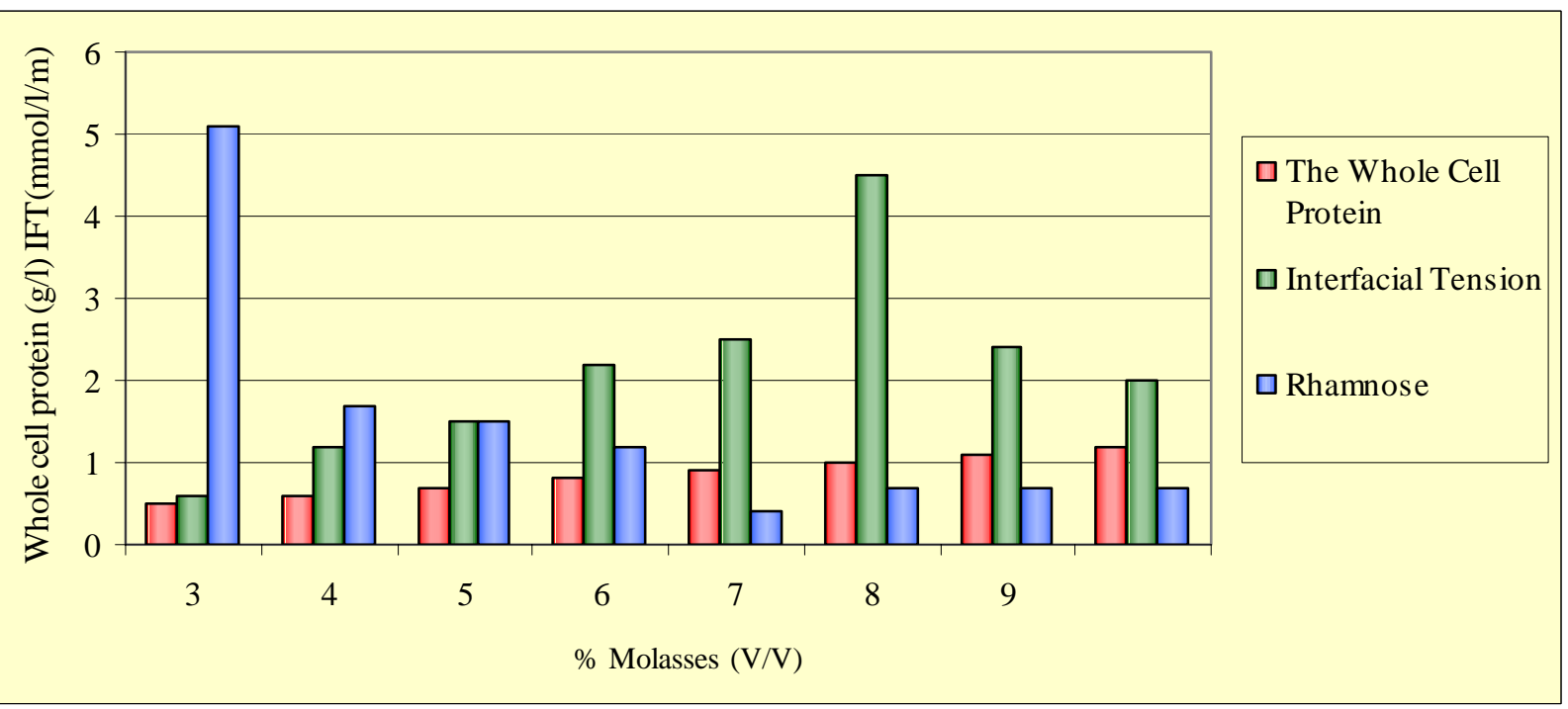

Figure 1: Effect of concentration of molasses on surfactant production were estimatated after $96 \mathrm{~h}$.of incubation IFT between medium and crude oil was $21 \mathrm{mmol} / \mathrm{lm}$

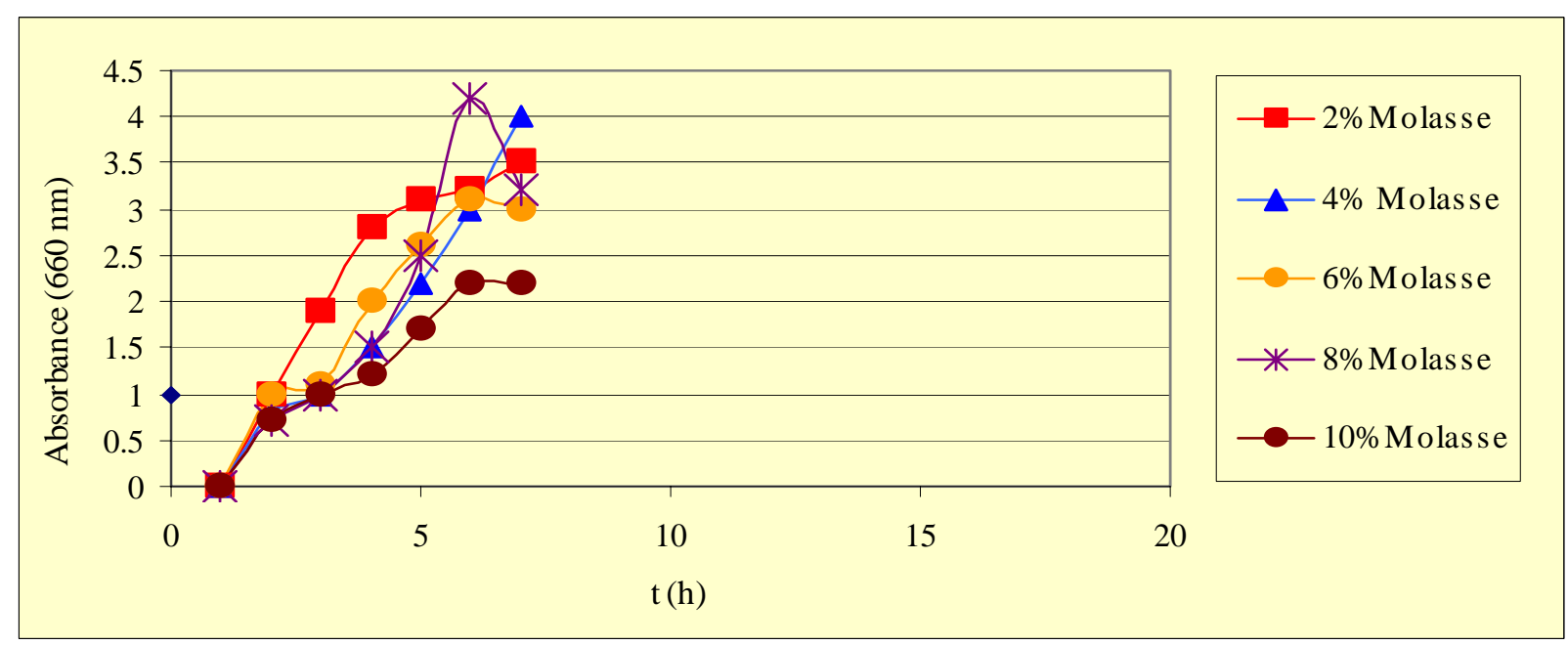

Figure 2: Growth of Pseudomonas aeruginosa at various concentration of molasses

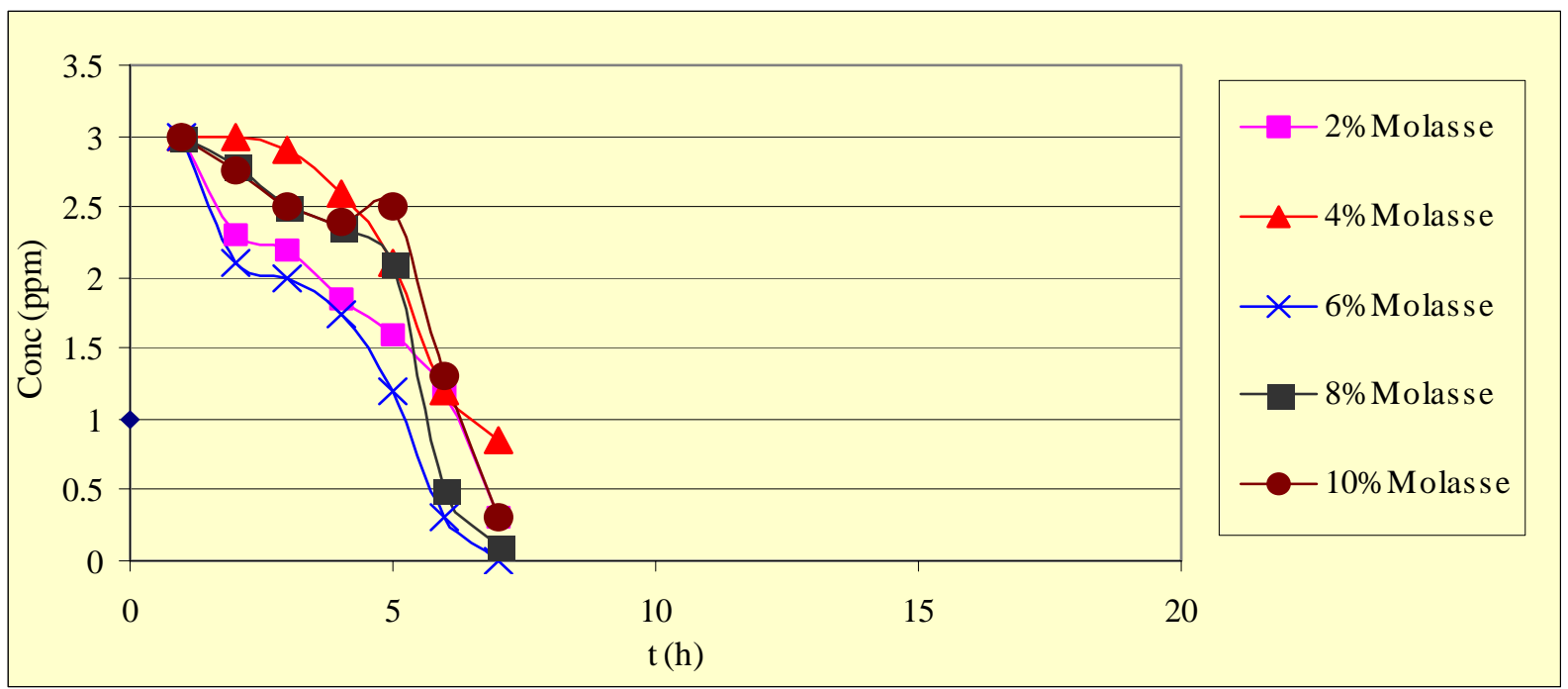

Figure 3: Uptake of nitrate at various concentrations of molasses 
Table 2: Yield of rhamnolipid at various concentration of molasses

\begin{tabular}{|c|c|c|}
\hline $\begin{array}{l}\text { Yield of rhamnolipid by } \\
\text { previous study,g } \\
\text { rhamnolipid/g biomass }\end{array}$ & Molasses & $\begin{array}{c}\text { Yp/x } \\
\text { (g rhamnolipid /gbiomass) }\end{array}$ \\
\hline & $2 \%$ & 0.003038 \\
$4 \%$ & 0.009642 \\
0.04 & $6 \%$ & 0.052805 \\
$8 \%$ & 0.040859 \\
& $10 \%$ & 0.21312 \\
\hline
\end{tabular}

\section{Discussion and Conclusion}

The waste product from sugar industry can be used as carbon source for rhamnolipid production in Pseudomonas aeruginosa fermentation.

In Figure 2 at low concentration of subtrate $( \pm$ $2 \%$ ), the specific production rate follows the model of Growth- associated which the production rate is similar to the growth rate. At higher substrate concentration $(>2 \%)$, the specific production rate follows the model of Mixed growth associated which showed that the production rate is not increasingly linier during the exponential phase, whereas at the stationary phase, the rate of rhamnolipid production is linier increase.

\section{References}

Andre, C., M. J. Espuny, M. Robert, M. E. Mercade, A. Manrresa, J. Guinea, A. V. Leeuwenhoek and J. Microbiol., in Press, Physicochemical characterization and antimicrobial properties of rhamnolipids produced by psuedomonas aeruginosa 47T2 NC BIM 40044. MIcrobial in press, 81 (3): 316322, 1998

Arino, S., R. Marchai and J. P. Van Decasteel, Identification and production of a rhamnolipidic biosurfactant by a Pseudomonas species, Appl. Microbial. Biotechnol., 45:162-168, 1996

Artiola, J. F., F. J. Ochoa-Loza and R. M. Maier, Stability constants for the complexation of various metals with a ramnolipid biosurfactant. J. Environ. Qual., 30 (2):479-85, 2001
Babu, P. S., A. N. Vaidya, A. S. Bai, R. kapur, A. Juwarkar and $P$. Khanna March, Kinetics of biosurfactant, production by Pseudomonas aeruginosa strain BS2 from industrial wastes, Biotech. Lett., 18, (3): 263268, 1996

Bai, G., L. M., Brusseau and R. M. Miller, Influence of rhamnolipid biosurfactants in: Biotechnology, 421457.

Beeba, J. L. and W. W. Umbreit, Microbial production of bio surfactants and their importance, J. Bacteriol, 108, 612, 1971

Burger, M. M., L. Glaser and R. M. Burton, Rhamnolipid production by psuedomonas aeruginosa from whey J. Biol. Chem., 238: 2595-2602,1963

Chayabutra, C., Jian Wu. and J. Lu. Kwang, Rhamnolipid production by Pseudomonas aeruginosa under denitrification: Effects of limiting nutrientsand carbon sources, Biotechnol. Bioeng., 72,(1), 25-33, 2001

Matsufuju, M., K. Nagata, and A.Yoshimoto, High production of rhamnolipids by Pseudomonas aeruginosa growing on ethanol,Biotech. Lett., 19 (12): 1213-1215,1997

Maier, R. M. and G. Soberon Chavez, Pseudomonas aeruginosa rhamnolipid: Biosynthesis and potential application, Appl. Microbiol. Biot.,54,625-633, 2000 